\title{
Optimization of injection parameters to obtain selected properties on foamed PP with hollow glass microspheres and thermally expandable microspheres using Taguchi method
}

Journal of Cellular Plastics 0 (0) $1-15$ (C) The Author(s) 2020

Article reuse guidelines: sagepub.com/journals-permissions DOI: I0.I I77/002I 955X20943097 journals.sagepub.com/home/cel SAGE

\section{Vicente Contreras',}

Francisco J Maturana², Jesús Poveda², Karina C Núñez ${ }^{2}$, Juan C Merino ${ }^{1,2}$ and José M Pastor ${ }^{1,2}$ (D)

\begin{abstract}
A foaming system composed by hollow glass microspheres (HGM) and thermally expandable microspheres (EM) was used to achieve a balance between selected properties of foamed polypropylene (PP) by injection molding, combining the higher flexural properties and lower density required on automotive interior parts. Taguchi's LI6 (44.23) was employed for the experimental plan and signal to noise ratio $(\mathrm{S} / \mathrm{N})$ for the optimization of the system raised. The two important injection molding parameters affecting selected properties were melt and mold temperature. The most important effect on flexural modulus was the amount of HGM, and for density the amount of EM.
\end{abstract}

\footnotetext{
'Department of Condensed Matter Physics, University of Valladolid, Valladolid, Spain

${ }^{2}$ Foundation for Research and Development in Transport and Energy (CIDAUT), Materials-Process-Product Area, Valladolid, Spain
}

Corresponding author:

José M Pastor, Universidad de Valladolid Escuela de Ingenierias Industriales, Paseo del Cauce 59, 470 II

Valladolid, Spain.

Email: jmpastor@fmc.uva.es 


\section{Keywords}

Polypropylene foams, injection molding, hollow glass microspheres, thermally expandable microspheres, Taguchi, DOE

\section{Introduction}

Currently there is an imperative need to accomplish the demand for lightweighting in the automotive market to reduce $\mathrm{CO}_{2}$ emissions to fulfill with regulations and international goals. ${ }^{1,2}$ In these circumstances it is important to develop and study novel materials to match technical requirements such as good mechanical properties with a reduction of weight in automotive applications. Due to the flexibility to produce huge varieties made of different polymers and additives as well as the possibility to be conformed under a wide range of foam characteristics (structure, density, etc), thermoplastic foams are potentially a good choice.

Polypropylene (PP) is one of the polymers used in the fabrication of thermoplastic foams. This material is highly demanded in the automotive industry, mainly related to its specific properties such as stiffness and tensile strength. ${ }^{3}$ Also, PP foams reinforced with nanoparticles are receiving attention because the nanoparticles improve foaming behavior. ${ }^{4,5}$ However, the characteristics of foamed PP depend on the technology applied in the foaming production. Thus, foamed material could suffer modifications according to the additives and foaming process involved. Therefore, these two variables must be considered to achieve the desired behavior in the final piece.

Injection molding allows the fabrication of detailed three-dimensional shaped plastic parts through high pressure injection of most of the polymeric materials into a cold mold. This technique is normally used for solid polymer processing in automotive industry at the present moment. Several injection foaming processes that have evolved from the traditional molding technique are currently being used for foam production. Nevertheless, foam injection molding is a complex process and has faced important challenges during its development which have restricted its potential applications. In the past decades, many special injection molding processes have been developed relating to these problems or to produce parts with special features. Some alternative processing technologies are presented as Mucell, ${ }^{6}$ Profoam, ${ }^{7}$ Stages Moulding, ${ }^{8}$ Pull and Foam, ${ }^{9}$ etc.

Although the use of these technologies allows a wide variety of pieces and significant weight reduction, in order to get parts with desired requirements, major changes in the process control or at the mold design must be accomplished. Therefore, the adaptation of these technologies at industrial level would not compensate the best achievements in the produced parts. Alternatively, a good way to fabricate parts according to the setting requirements would be by means of traditional foaming injection molding through optimization of the process variables (materials, additives and processing parameters). ${ }^{10,11}$ 
The production of thermoplastic foams by injection molding is accomplished with the assistance of blowing agents, which can be dosed into the base material in different ways. The traditional blowing agents are basically classified into chemical and physical. The chemical ones are mixed in solid form with the polymer pellets and decomposed by heat during the processing. ${ }^{12}$

The use of thermally expandable microspheres as blowing agent is currently proved to be a valid option for this type of application. Recent studies with microspheres composed of a low boiling point hydrocarbon surrounded by a polymeric shell, have been modified and applied to foam PP by injection molding, achieving interesting results in terms of reduced cell size and uniform distribution. ${ }^{13,14}$

Microspheres incorporated as blowing agent in thermoplastic polymer are capable to expand to $50-100$ times greater than their initial volume when the polymer is processed at melt temperature. One of the major advantages of using microspheres for plastic foaming, especially for foam injection molding, is to prevent the two main problems that exist using the traditional blowing agents (bubble eruption and breakup at the flow front) improving the aspect of the injected samples surface. On the other hand, this kind of microspheres can not be easily processed by injection molding at temperatures over $210^{\circ} \mathrm{C}$ at which foam injection molding of PP is often conducted. However, in order to increase its range of applicability in the automotive industry, this manufacturing process is still being investigated with the objective of improving the properties of thermally expandable microspheres. ${ }^{15-17}$

In order to improve the performance of foamed PP with thermally expandable microspheres as blowing agents, so as to fulfill the stiffness requirements on internal automotive parts made of this material, it is necessary to evaluate the possibility to add some filler to improve the specific mechanical properties under optimal conditions for processing.

Among the various types of reinforcing fillers that exist for PP, hollow glass microspheres would become an interesting alternative in this case, because it could keep its characteristics of reinforced particles contributing to the stiffness required on the material, without adversely affecting the density reduction achieved.

In the last two decades hollow glass microspheres have been studied as the main component of syntactic foam of various thermoplastic and thermoset materials. As any other filler with these characteristics, the treatment of the spheres to compatibilize with the polymer has been studied. ${ }^{18-21}$

On this work a combined foam system using hollow glass microspheres (HGM) and thermally expandable microspheres (EM) has been obtained. For this system, the influence of the foaming injection parameters (melt temperature, injection rate, back pressure, mold temperature, screw rotation speed) and the percentage of EM and HGM on flexural modulus and density have been analyzed. The aim of this work is to use the Taguchi DOE (Design Of Experiments) methodology on injected specimens to complete this study.

The Taguchi DOE methodology that has been used in the study allows to assess the main variables related to the injection foam process through a feasible number 
of experiments (16 in this case, instead of the 2.048 that would be required if the study had been made by means of a full factorial experiment).

Taguchi's $\mathrm{L}_{16}\left(4^{4} .2^{3}\right)$ orthogonal array design was employed for the experimental plan and signal to noise $(\mathrm{S} / \mathrm{N})$ ratio for the optimization of the system obtained, whereas the best balance between the flexural stiffness and reduced density features required in automotive parts is achieved.

\section{Experimental}

\section{Materials and preparation of HGM PP masterbatch}

A polypropylene (PP) with melt flow index of $15 \mathrm{~g} / 10 \mathrm{~min}$, density of $0.905 \mathrm{~g} / \mathrm{cm}^{3}$ and flexural modulus of $1290 \mathrm{MPa}$ was used for the experiments and for masterbatch preparation. Thermally expandable microspheres masterbatch Advancell P501M1 commercial grade supplied by Sekisui Chemical were used. The thermally expandable microspheres (EM) consist of a polymeric skin (generally acrylic) and a hollow core filled with a blowing agent (hydrocarbon). When temperature increases, the hydrocarbon internal pressure grows and the microsphere expands. If the temperature reaches a critical value, the skin breaks and the microspheres explode releasing the hydrocarbon (Figure 1). This is an undesirable effect.
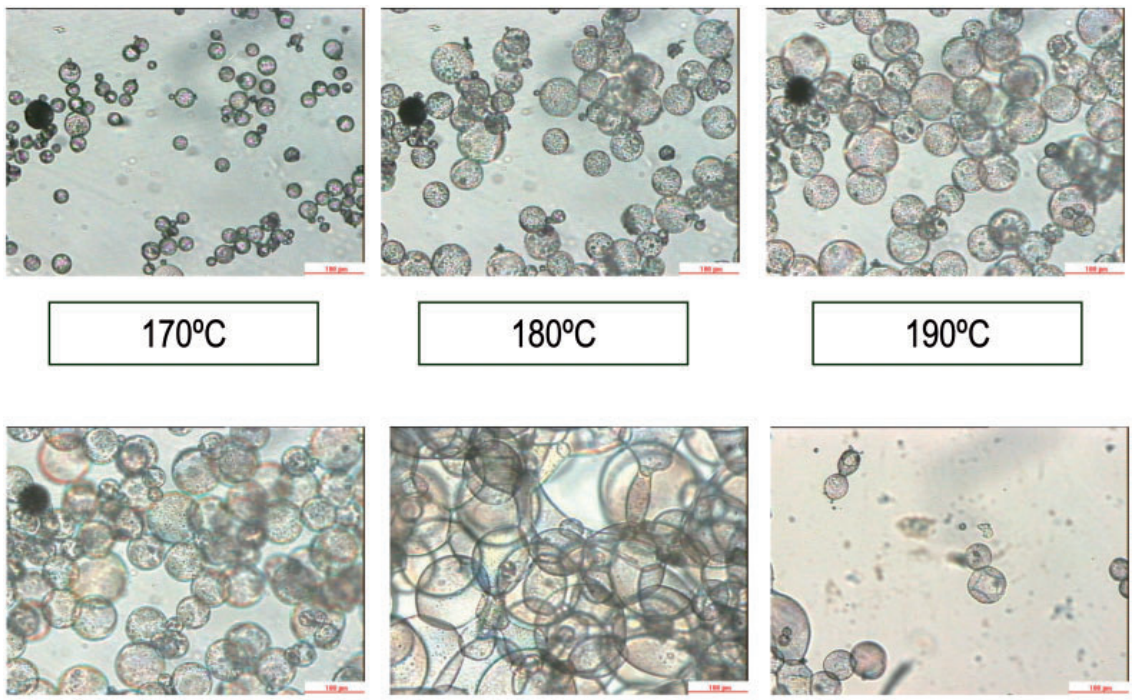

$200^{\circ} \mathrm{C}$

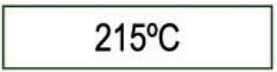

$230^{\circ} \mathrm{C}$

Figure I. Growth of the expandable microspheres (EM) with the temperature. 
The preparation of the HGM PP was made with commercial hollow glass microspheres im $30 \mathrm{k}$ supplied by $3 \mathrm{M}$ Company. Additionally, a commercial maleic anhydride grafted PP Polybond 3200 was employed as coupling agent.

The hollow glass microspheres masterbatch was prepared in a Leistritz Micro $27 \mathrm{GL}$ corrotating twin-screw extruder at $210^{\circ} \mathrm{C}$ (die temperature) and $60 \mathrm{rpm}$. In the masterbatch preparation, the grafted PP (2 wt. \%) and the PP (88wt. \%) were fed through the main hopper at first port of the extruder and the hollow glass microspheres $(10 \mathrm{wt} . \%)$ through the second port. The solid materials (raw polymers) were starved fed to the extruder by a solid feeder and the extrudates were cooled in a water bath and pelletized afterwards. The effective content of microspheres in the masterbatch was determined by thermogravimetric analysis (TGA) and their integrity was verified by scanning electronic microscopy (SEM).

\section{Taguchi array and process methodology}

The effects of the molding process parameters based on the Taguchi's orthogonal design could be determined effectively from matrix experiments. By applying Taguchi method based on orthogonal arrays, time and cost required for conducting of the experiments can be reduced. Taguchi method recommends the use of the $(\mathrm{S} / \mathrm{N})$ ratio for determination of the quality characteristics implemented in engineering design problems. The $\mathrm{S} / \mathrm{N}$ ratio characteristics with signed-target type can be divided into three stages: the smaller is better, the nominal is the best, and the larger is better. ${ }^{22}$ In our study, the $\mathrm{S} / \mathrm{N}$ ratio for the density was calculated under the premise smaller is better for determining the effect of process parameters on density values and the optimal point. The formula of $\mathrm{S} / \mathrm{N}$ ratio is shown in equation (1).

$$
S / N=-10 \cdot \log \left[\frac{1}{n}\left(\sum_{i=1}^{n} y_{i}^{2}\right)\right]
$$

where $y_{i}$ is the measured experimental result and $n$ refers to the number of specimens in each test trial. ${ }^{22,23}$

Similarly, the $\mathrm{S} / \mathrm{N}$ ratio for the flexural modulus was calculated under the premise larger is better for determining the optimal point for flexural modulus when the objective is to find the highest modulus. The formula of $\mathrm{S} / \mathrm{N}$ ratio in this case is shown in equation (2).

$$
S / N=-10 \cdot \log \left[\frac{1}{n}\left(\sum_{i=1}^{n} \frac{1}{y_{i}^{2}}\right)\right]
$$

Tests were organized using Taguchi's $\mathrm{L}_{16}\left(4^{4} \cdot 2^{3}\right)$ orthogonal array (Table 1). The orthogonal array selected allows to study the main effects of each parameter 
Table I. An orthogonal array $L_{16}\left(4^{4} \cdot 2^{3}\right)$ of Taguchi.

\begin{tabular}{|c|c|c|c|c|c|c|c|c|}
\hline \multirow[b]{2}{*}{ Experiment $\mathrm{N}^{\circ}$} & \multicolumn{7}{|c|}{ Factor } & \\
\hline & $A$ & B & C & $\mathrm{D}$ & $E$ & $\mathrm{~F}$ & G & \\
\hline I & $\mathrm{I}$ & I & 1 & 1 & I & I & 1 & \\
\hline 2 & 1 & 2 & 2 & 2 & I & 2 & 2 & \\
\hline 3 & 1 & 3 & 3 & 3 & 2 & I & 2 & \\
\hline 4 & I & 4 & 4 & 4 & 2 & 2 & 1 & \\
\hline 5 & 2 & 1 & 2 & 3 & 2 & 2 & I & \\
\hline 6 & 2 & 2 & I & 4 & 2 & I & 2 & \\
\hline 7 & 2 & 3 & 4 & 1 & 1 & 2 & 2 & \\
\hline 8 & 2 & 4 & 3 & 2 & I & 1 & 1 & \\
\hline 9 & 3 & 1 & 3 & 4 & I & 2 & 2 & \\
\hline 10 & 3 & 2 & 4 & 3 & i & I & 1 & \\
\hline 11 & 3 & 3 & 1 & 2 & 2 & 2 & 1 & \\
\hline 12 & 3 & 4 & 2 & 1 & 2 & I & 2 & \\
\hline 13 & 4 & i & 4 & 2 & 2 & I & 2 & \\
\hline 14 & 4 & 2 & 3 & 1 & 2 & 2 & 1 & \\
\hline 15 & 4 & 3 & 2 & 4 & I & I & 1 & evel \\
\hline 16 & 4 & 4 & I & 3 & 1 & 2 & 2 & \\
\hline
\end{tabular}

on the selected properties. Statistical analysis was made using MINITAB ${ }^{\circledR} 16$ software. In this study, the larger is better approach was used for maximizing flexural modulus and the smaller is better for minimizing density.

To perform all the experiments, the parameters of conventional injection molding in addition to the content of expandable microspheres and hollow glass microspheres were considered. Injection molding was carried out in a Krauss Maffei KM 200-700/90CZ, incorporating a shut off nozzle that reduced leakage and escape of material from the plasticizing section after injection. All experimental injection conditions were performed employing physical blends of the selected elements (neat PP, HGM and EM masterbatch). The cavity was partially filled with molten material, so that the expansion of the material could conform and complete the filling of mold at the end part of the process, consequently this foaming process could be achieved without using packing pressure.

The process parameters and levels are shown in Table 2. Melt temperatures were taken from the range where the microspheres could expand without collapse or breakage of the skin $\left(170-215^{\circ} \mathrm{C}\right)$ (Figure 1). In order to achieve optimal foam the range of EM content used in the design was based on recommendations made by the manufacturer of the microspheres $(0.5-3 \mathrm{wt}$. \%). On the other hand, the range of HGM used was from zero to $6 \mathrm{wt} . \%$. This selected limit corresponds to the maximum amount to be added for achieving the reinforcement according to the recommendation of the manufacturer. Injection rates were selected in an interval between lower and higher values set on the injection machine $(15-120 \mathrm{~mm} / \mathrm{s})$. All the ranges used in the above mentioned parameters were divided in four levels 
Table 2. The process parameters (factors) and levels.

\begin{tabular}{|c|c|c|c|c|c|c|}
\hline \multirow[b]{2}{*}{ Factor } & \multirow[b]{2}{*}{ Parameter } & \multirow[b]{2}{*}{ Unit } & \multicolumn{4}{|c|}{ Level } \\
\hline & & & 1 & 2 & 3 & 4 \\
\hline$A$ & Melt temperature & ${ }^{\circ} \mathrm{C}$ & 170 & 185 & 200 & 215 \\
\hline B & EM content & $\%^{\mathrm{a}}$ & 0,5 & $\mathrm{I}, 3$ & 2,1 & 3 \\
\hline C & Injection velocity & $\mathrm{mm} / \mathrm{s}$ & 15 & 50 & 85 & 120 \\
\hline $\mathrm{D}$ & HGM content & $\%^{a}$ & 0 & 2 & 4 & 6 \\
\hline E & Back pressure & bar & 20 & 80 & - & - \\
\hline $\mathrm{F}$ & Mold temperature & ${ }^{\circ} \mathrm{C}$ & 30 & 60 & - & - \\
\hline G & Screw speed & rpm & 50 & 100 & - & - \\
\hline
\end{tabular}

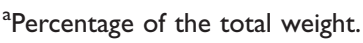

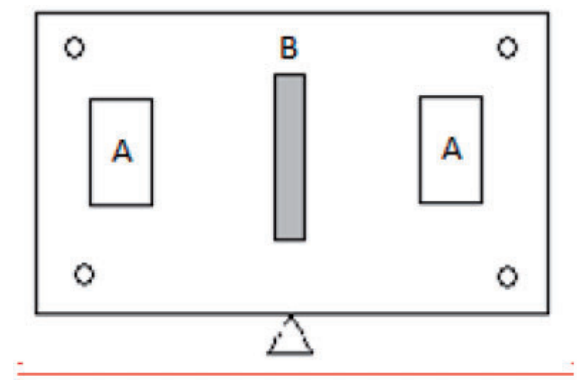

Figure 2. Specimen distribution in injected plates. Specimens for flexural tests were located in both sides (right and left) and the specimens for the density test were taken from the shaded zone at the center of the plate.

within the limits indicated in each case. Similar considerations taken on injection rates were used for back pressure $\left(20-80\right.$ bar), mold temperature $\left(30-60^{\circ} \mathrm{C}\right)$ and screw rotation speed $(50-100 \mathrm{rpm})$ in order to distinguish between melt homogenization, residence time (back pressure, screw rotation speed) and sample cooling (mold temperature). Finally, packing pressure and time were suppressed from injection molding and cooling time was constant at $30 \mathrm{~s}$ for all experiments.

\section{Preparation and characterization of samples}

Experimental samples were obtained from $166 \times 120(\mathrm{~mm})$ injected plates with $2.5 \mathrm{~mm}$ thick and the specimens for flexural and density test were prepared by cutting the plates according to Figure 2. The thickness of the interior plastic parts currently used in the automotive sector is around $2.5 \mathrm{~mm}$. This thickness allows us to achieve an optimum balance between mechanical properties and plastic parts feasible within an injection process. 
Table 3. Experimental conditions and corresponding density and flexural modulus measurement results.

\begin{tabular}{|c|c|c|c|c|c|c|c|c|c|}
\hline $\begin{array}{l}\text { Experiment } \\
N^{\circ}\end{array}$ & $\begin{array}{l}\text { Melt } \\
\text { temperature } \\
\left({ }^{\circ} \mathrm{C}\right)\end{array}$ & \% EM & $\begin{array}{l}\text { Injection } \\
\text { velocity } \\
(\mathrm{mm} / \mathrm{s})\end{array}$ & \% HGM & $\begin{array}{l}\text { Back } \\
\text { pressure } \\
\text { (bar) }\end{array}$ & $\begin{array}{l}\text { Mold } \\
\text { temperature } \\
\left({ }^{\circ} \mathrm{C}\right)\end{array}$ & $\begin{array}{l}\text { Screw } \\
\text { speed } \\
\text { (rpm) }\end{array}$ & $\begin{array}{l}\text { Flexural } \\
\text { modulus } \\
(\mathrm{MPa})\end{array}$ & $\begin{array}{l}\text { Density } \\
\left(\mathrm{g} / \mathrm{cm}^{3}\right)\end{array}$ \\
\hline I & 170 & 0.5 & 15 & 0 & 20 & 30 & 50 & 1204 & 0.893 \\
\hline 2 & 170 & 1.3 & 50 & 2 & 20 & 60 & 100 & 1395 & 0.891 \\
\hline 3 & 170 & 2.1 & 85 & 4 & 80 & 30 & 100 & 1283 & 0.860 \\
\hline 4 & 170 & 3.0 & 120 & 6 & 80 & 60 & 50 & 1390 & 0.848 \\
\hline 5 & 185 & 0.5 & 50 & 4 & 80 & 60 & 50 & 1398 & 0.879 \\
\hline 6 & 185 & 1.3 & 15 & 6 & 80 & 30 & 100 & 1405 & 0.856 \\
\hline 7 & 185 & 2.1 & 120 & 0 & 20 & 60 & 100 & 1233 & 0.886 \\
\hline 8 & 185 & 3.0 & 85 & 2 & 20 & 30 & 50 & 1222 & 0.852 \\
\hline 9 & 200 & 0.5 & 85 & 6 & 20 & 60 & 100 & 1442 & 0.867 \\
\hline 10 & 200 & 1.3 & 120 & 4 & 20 & 30 & 50 & 1302 & 0.869 \\
\hline II & 200 & 2.1 & 15 & 2 & 80 & 60 & 50 & 1299 & $0.88 I$ \\
\hline 12 & 200 & 3.0 & 50 & 0 & 80 & 30 & 100 & 1096 & 0.856 \\
\hline 13 & 215 & 0.5 & 120 & 2 & 80 & 30 & 100 & 1223 & 0.886 \\
\hline 14 & 215 & 1.3 & 85 & 0 & 80 & 60 & 50 & 1107 & 0.892 \\
\hline 15 & 215 & 2.1 & 50 & 6 & 20 & 30 & 50 & 1275 & 0.854 \\
\hline \multirow[t]{2}{*}{16} & 215 & 3.0 & 15 & 4 & 20 & 60 & 100 & 1328 & 0.855 \\
\hline & & & & & & & Average & 1288 & 0.870 \\
\hline
\end{tabular}

The distribution of test specimens from the same plate leads to characterize both properties (flexural modulus and density) without influence of other uncontrolled parameters (noise). Rectangle specimens of $50 \times 25(\mathrm{~mm})$ (Figure 2(A)) were tested at $1 \mathrm{~mm} / \mathrm{min}$ in a 3-points bending experiment for the determination of flexural modulus (ISO 178 method) in an INSTRON 3365 (Universal testing machine). The bulk density was obtained from water displacement of $10 \times 10(\mathrm{~mm})$ specimens (ISO 1183-1 method) from the central zone of the injected plates (Figure 2 (B)) in a Mettler Toledo AX205DR scales. In both cases, the tests were repeated five times and the mean values were presented. Table 3 shows the experimental conditions and the density and flexural modulus results.

\section{Results and discussion}

\section{Density measurement results}

It should be noted that all the experimental density values are lower than density of neat PP. Meanwhile, it can be observed that these values are determined by two main process parameters, the amount of hollow glass microspheres and of expandable microspheres. In order to study the effect of each variable on the foamed material properties the main effects graph for density are shown in Figure 3. The density values go down when the amount of both types of microspheres increases, and a higher effect on density values with expandable microspheres content is 
Flexural Modulus - EM/HGM system

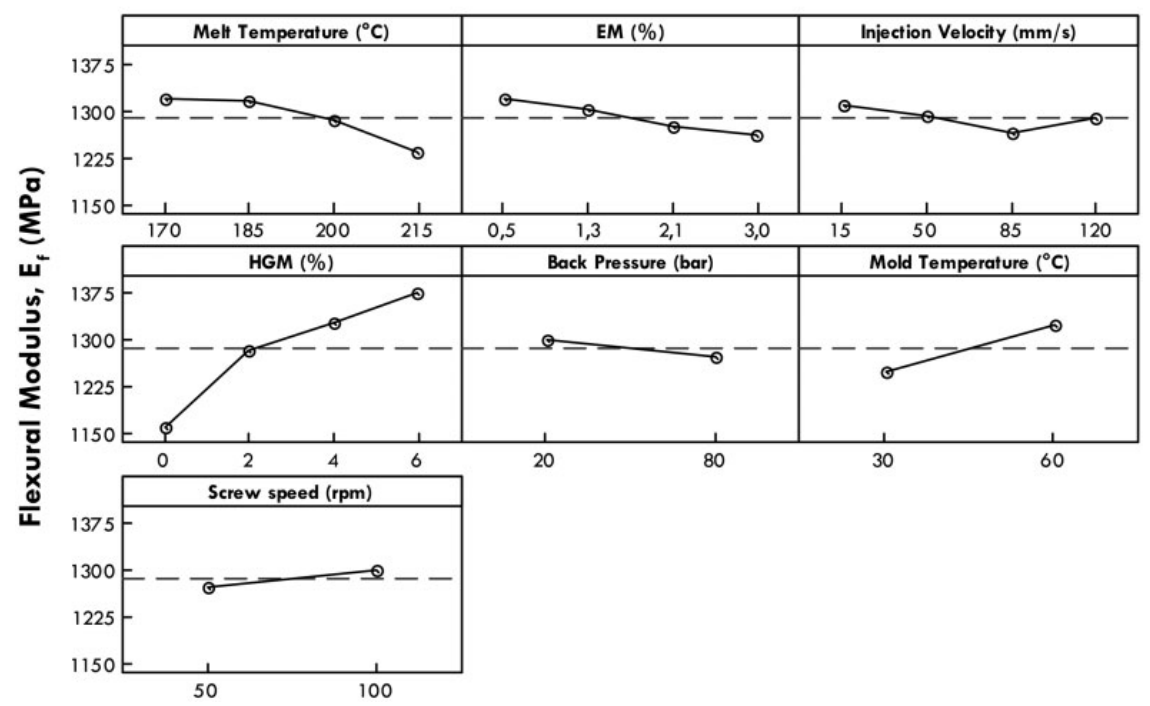

Figure 3. Main effects graph for flexural modulus as function of process parameters.

Table 4. Response table for means values for density as function of process parameters.

\begin{tabular}{lllllllll}
\hline & Factor & $\mathrm{A}$ & $\mathrm{B}$ & $\mathrm{C}$ & $\mathrm{D}$ & $\mathrm{E}$ & $\mathrm{F}$ & $\mathrm{G}$ \\
\hline LEVEL & $\mathrm{I}$ & 0.873 & $0.88 \mathrm{I}$ & $0.87 \mathrm{I}$ & 0.882 & $0.87 \mathrm{I}$ & $\mathbf{0 . 8 6 6}$ & $0.87 \mathrm{I}$ \\
& 2 & $\mathbf{0 . 8 6 8}$ & 0.877 & 0.870 & 0.878 & $\mathbf{0 . 8 7 0}$ & 0.875 & $\mathbf{0 . 8 7 0}$ \\
& 3 & 0.868 & 0.870 & $\mathbf{0 . 8 6 8}$ & 0.866 & & & \\
& 4 & 0.872 & $\mathbf{0 . 8 5 3}$ & 0.872 & $\mathbf{0 . 8 5 6}$ & & & \\
Delta & & 0.005 & 0.028 & 0.004 & 0.026 & $0.00 \mathrm{I}$ & 0.009 & $0.00 \mathrm{I}$ \\
Rank & & 4 & $\mathrm{I}$ & 5 & 2 & 7 & 3 & 6 \\
\hline
\end{tabular}

observed. This result could be verified with mean values in Table 4 (the optimal combination of parameters that minimize the result of density has been the bold numbers: A2, B4, C3, D4, E2, F1, G2), obtaining a maximum weight reduction for the percentage of EM and HGM at the level 4 on the DOE $(3 \%$ and $6 \%$ respectively). Therefore, in relative terms it is possible to achieve an increase of the specific flexural modulus of around 26\%. The important contribution from HGM content to the density values is a consequence of the lightweight filler characteristics; this fact has notorious influence on the reduction of the density values. This kind of microspheres could provoke this effect as long as its integrity is preserved during processing without crushed particles. ${ }^{24,25}$

Based on the $\mathrm{S} / \mathrm{N}$ ratio obtained for the density (equation (1)), the best combination of process parameters to get a lower density is represented for the highest 
Table 5. S/N ratio results of density test.

\begin{tabular}{lllllllll}
\hline & Factor & $\mathrm{A}$ & $\mathrm{B}$ & $\mathrm{C}$ & $\mathrm{D}$ & $\mathrm{E}$ & $\mathrm{F}$ & $\mathrm{G}$ \\
\hline LEVEL & $\mathrm{I}$ & $\mathrm{I} .18 \mathrm{I}$ & $\mathrm{I} .099$ & 1.198 & 1.095 & 1.201 & 1.252 & 1.201 \\
& 2 & 1.229 & 1.141 & 1.212 & 1.136 & 1.213 & 1.162 & 1.214 \\
& 3 & 1.226 & 1.208 & 1.230 & 1.251 & & & \\
& 4 & 1.193 & $1.38 \mathrm{I}$ & 1.189 & 1.347 & & & \\
\hline
\end{tabular}

values of $\mathrm{S} / \mathrm{N}$ ratio for each factor. In this case, the combination of process parameters to get the lowest density for this foaming system is presented by $\mathrm{A}_{2}$, $\mathrm{B}_{4}, \mathrm{C}_{3}, \mathrm{D}_{4}, \mathrm{E}_{2}, \mathrm{~F}_{1}, \mathrm{G}_{2}$ (bold numbers at Table 5) i.e. melt temperature (A) at level 2 $\left(185^{\circ} \mathrm{C}\right), \mathrm{EM}$ content $(\mathrm{B})$ at level $4(3 \%)$, etc.

Some injection parameter values (melt temperature, injection rate and screw speed) found for a reduction in the density of the material are associated with the EM characteristics. A higher residence time or melt temperature could lead to an adverse effect due to the deterioration of the surfaces of microspheres that could cause an shrinkage of them over temperature. ${ }^{26}$

\section{Flexural measurement results}

It may be noted that in half of the experiments it was achieved equal or higher flexural modulus values than neat PP (Table 3), which means that there could be more than one process parameters combination where the same or better flexural modulus for the material with a density reduction (higher flexural modulus against density) could be achieved.

Regarding the most determinant factor in the behavior of the flexural modulus, HGM content is the parameter with bigger influence on the values of flexural modulus for all range of study (Figure 4). Also, injection parameters like melt and mold temperature have an important effect on flexural modulus. These results are shown with mean values in Table 6 . In our range of study the highest difference belongs to HGM content with $16 \%$ between the maximum and minimum flexural modulus, with higher modulus for level 1.

As it is can be observed in Figure 4, melt temperature is the most affecting parameter on the flexural modulus. Then, the following most significant process variables are the mold temperature, the injection rate and the screw speed. The variable process that has proved less significant is the back pressure.

The optimal combination of parameters that maximizes the result of flexural modulus has been: A1, B1, C1, D4, E1, F2, G2 (Melt Temperature $170^{\circ} \mathrm{C}$, EM Content $0.5 \%$, Injection Rate $15 \mathrm{~mm} / \mathrm{s}$, HGM Content 6\%, Back Pressure 20 bar, Mold Temperature $60^{\circ} \mathrm{C}$, Screw Speed $100 \mathrm{rpm}$ ). This combination resulted (see Table 8) in a flexural modulus of $1590 \mathrm{MPa}$, a $23.3 \%$ increase from the $1290 \mathrm{MPa}$ reference value. The flexural modulus was evaluated in terms of $\mathrm{S} / \mathrm{N}$ ratio, as it was done for the density. Based on $\mathrm{S} / \mathrm{N}$ ratio for the flexural modulus (equation (2)), the best combination of process parameters to get a higher flexural modulus for 


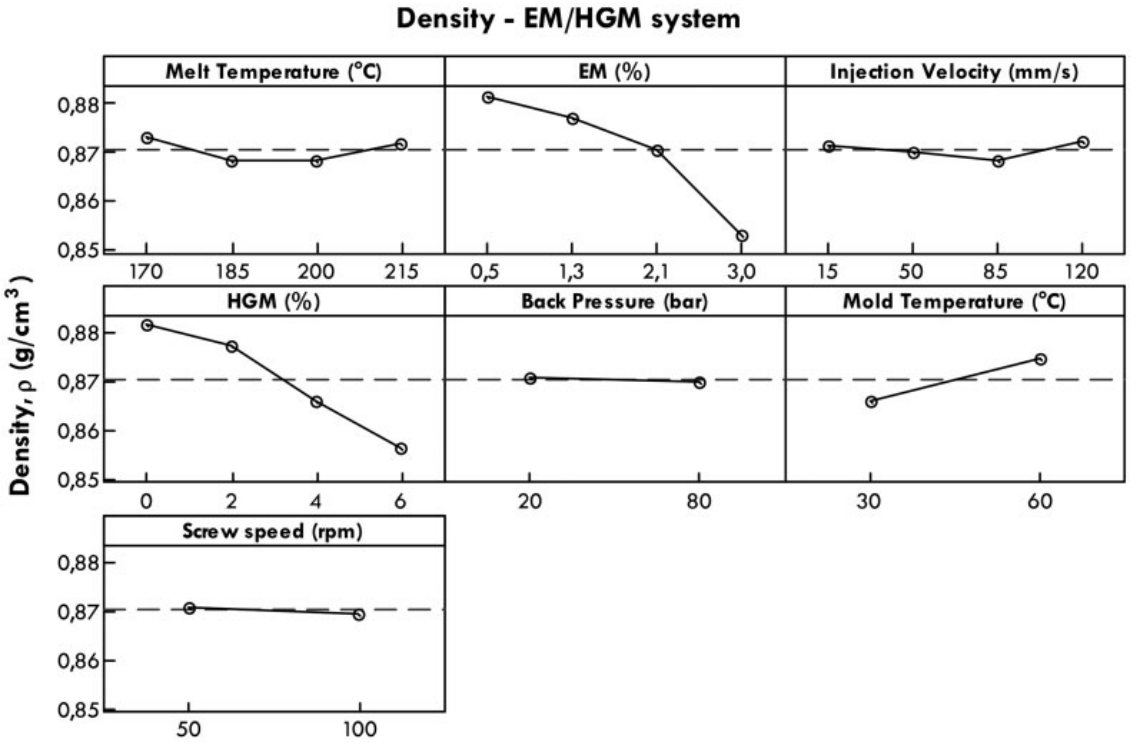

Figure 4. Main effects graph for density as function of process parameters.

Table 6. Response table for means values for flexural modulus as function of process parameters.

\begin{tabular}{|c|c|c|c|c|c|c|c|c|}
\hline & Factor & $A$ & B & C & $D$ & $E$ & $\mathrm{~F}$ & G \\
\hline \multirow[t]{4}{*}{ LEVEL } & 1 & 1318 & 1317 & 1309 & 1160 & 1300 & $|25|$ & 1275 \\
\hline & 2 & 1314 & 1302 & 1291 & 1285 & 1275 & 1324 & $|30|$ \\
\hline & 3 & 1285 & 1273 & 1263 & 1328 & - & - & - \\
\hline & 4 & 1233 & 1259 & 1287 & 1378 & - & - & - \\
\hline Delta & & 85 & 58 & 46 & 218 & 25 & 73 & 26 \\
\hline Rank & & 2 & 4 & 5 & I & 7 & 3 & 6 \\
\hline
\end{tabular}

this foaming system is presented by $A_{1}, B_{1}, C_{1}, D_{4}, E_{1}, F_{2}, G_{2}$ (bold numbers at Table 7) i.e. melt temperature (A) at level $1\left(170^{\circ} \mathrm{C}\right)$, EM content (B) at level 1 $(0.5 \%)$, etc.

\section{Confirmation and comparisons tests}

The confirmation test is used to verify the estimated result obtained from analysis with Taguchi method in relation to the experimental results. If the optimal combination of parameters and their levels match with one of the experiments in the orthogonal array, then the confirmatory test is not required. 
Table 7. $\mathrm{S} / \mathrm{N}$ ratio results of flexural test.

\begin{tabular}{lllllllll}
\hline & Factor & A & B & C & D & E & F & G \\
\hline LEVEL & I & $\mathbf{6 2 . 3 8}$ & $\mathbf{6 2 . 3 6}$ & $\mathbf{6 2 . 3 3}$ & 61.28 & $\mathbf{6 2 . 2 6}$ & 61.93 & $\mathbf{6 2 . 0 8}$ \\
& 2 & 62.36 & 62.25 & 62.18 & 62.17 & 62.07 & $\mathbf{6 2 . 4 1}$ & $\mathbf{6 2 . 2 5}$ \\
& 3 & 62.14 & 62.09 & 61.99 & 62.46 & - & - & - \\
& 4 & 61.80 & 61.97 & 62.18 & $\mathbf{6 2 . 7 7}$ & - & - & - \\
\hline
\end{tabular}

Table 8. Results of confirmatory experiments (density and flexural tests).

\begin{tabular}{lllllll}
\hline & & & & \multicolumn{2}{c}{ Error } \\
Test & Factor ${ }_{\text {Level }}$ & Properties & \multicolumn{2}{c}{ Experiment } & Estimation & Difference $(\%)$ \\
\hline Minimum density & $\mathrm{A}_{2}, \mathrm{~B}_{4}, \mathrm{C}_{3}, \mathrm{D}_{4}, \mathrm{E}_{2}$, Density $\left(\mathrm{g} / \mathrm{cm}^{3}\right)$ & 0.834 & 0.829 & 0.005 & 0.59 \\
& $\mathrm{~F}_{1}, \mathrm{G}_{2}$ & Flexural modulus $(\mathrm{MPa})$ & 1360 & 1316 & 44 & 3.34 \\
$\begin{array}{c}\text { Maximum flexural } \\
\text { modulus }\end{array}$ & $\mathrm{A}_{1}, \mathrm{~B}_{1}, \mathrm{C}_{1}, \mathrm{D}_{4}, \mathrm{E}_{1}$, Density $\left(\mathrm{g} / \mathrm{cm}^{3}\right)$ & 0.885 & 0.875 & 0.010 & 1.14 \\
& $\mathrm{~F}_{2}, \mathrm{G}_{2}$ & Flexural modulus $(\mathrm{MPa})$ & 1590 & 1521 & 69 & 4.53 \\
\hline
\end{tabular}

Estimated value of density and flexural modulus at two different conditions was calculated by adding the average performance to the contribution of each parameter at the optimum level using the following equations: ${ }^{27}$

$$
\begin{gathered}
\text { Yopt }=\mathrm{m}+\left(\mathrm{m}_{\text {Aopt }}-\mathrm{m}\right)+\left(\mathrm{m}_{\text {Bopt }}-\mathrm{m}\right)+\left(\mathrm{m}_{\mathrm{Copt}}-\mathrm{m}\right) \\
+\left(\mathrm{m}_{\text {Dopt }}-\mathrm{m}\right)+\left(\mathrm{m}_{\text {Eopt }}-\mathrm{m}\right)+\left(\mathrm{m}_{\text {Fopt }}-\mathrm{m}\right)+\left(\mathrm{m}_{\mathrm{Gopt}}-\mathrm{m}\right) \\
\mathrm{m}=\frac{\mathrm{T}}{\mathrm{n}}
\end{gathered}
$$

where $\mathrm{m}$ is the average performance of each property, $\mathrm{T}$ is the grand total of selected property for each experiment, $\mathrm{n}$ is the total number of experiments and $\mathrm{m}_{\text {Aopt }}$ is the average property for factor $\mathrm{A}$ at its optimum level and so on for other factors. After defining these optimal conditions, one try at the optimal combination of parameters and their levels was realized in order to validate the DOE's prediction capabilities. For example, density values for optimal condition of "minimum density" belong to this combination $A_{2}, B_{4}, C_{3}, D_{4}, E_{2}, F_{1}$ and $G_{2}$. These values and the obtained for the flexural modulus are shown in Table 8.

On the same Table it can be observed that the estimated and calculated results had very close values with the experimental results, and for statistical analyses, these error values were in an acceptable range in both cases. ${ }^{22}$

An estimated value of density of $0.875 \mathrm{~g} / \mathrm{cm}^{3}$ was found in the test condition "maximum flexural modulus" that represents the incorporation of the highest HGM content and the lowest EM content in the studied range. If HGM of a density of $0.600 \mathrm{~g} / \mathrm{cm}^{3}$ was only used into the final material, it could reach a 
material with density of $0.878 \mathrm{~g} / \mathrm{cm}^{3}$, with the lowest content of crushed microspheres during processing. This value is similar to the density obtained in the optimal condition "maximum flexural modulus". In this case, the material has the smallest possible amount of EM combined with the maximum amount of HGM, a fact that would validate the estimates made by Taguchi if it is compared with an estimated density value for only HGM material. Moreover, when the addition of EM is 3\%, as in the case of "minimum density", the estimated density value drops more than $5 \%$ in relation to the previous condition. This demonstrates the importance of the incorporation of the blowing agent (EM) in such materials to find the highest density reduction. Finally the condition "minimum density" could fulfill the expectations about optimization of the injection parameters, because this material reaches a higher flexural modulus with a lower density (higher flexural modulus against density) compared with neat PP.

\section{Conclusions}

The Taguchi experimental method was used to investigate the influence of the injection parameters and microspheres content on selected properties (density and flexural modulus) of foamed PP. This method allows to determine the optimum condition of process parameters on foaming injection molding of PP to achieve materials with a minimum density with the maximum flexural modulus. The most important parameters affecting the minimum density were EM and HGM content. The other parameters affecting the density values were lower and closed to each other. In the case of maximum flexural modulus, the most important parameter was the HGM content.

On this work is reflected the influence of each studied variable on the flexural modulus and density of the foamed PP. Thus, a specific material will be obtained with the minimum density of $0.834 \mathrm{~g} / \mathrm{cm}^{3}$ with the factors and levels combined as $\mathrm{A}_{2}, \mathrm{~B}_{4}, \mathrm{C}_{3}, \mathrm{D}_{4}, \mathrm{E}_{2}, \mathrm{~F}_{1}, \mathrm{G}_{2}$, i.e. melt temperature $\left(185^{\circ} \mathrm{C}\right), \mathrm{EM}$ content $(3 \%)$, injection rate $(85 \mathrm{~mm} / \mathrm{s})$, HGM content $(6 \%)$, back pressure $(80 \mathrm{bar})$, mold temperature $\left(30^{\circ} \mathrm{C}\right)$ and screw rotation speed $(100 \mathrm{rpm})$. The optimum flexural modulus is $1521 \mathrm{MPa}$ with the factors and level combined as $\mathrm{A}_{1}, \mathrm{~B}_{1}, \mathrm{C}_{1}, \mathrm{D}_{4}, \mathrm{E}_{1}, \mathrm{~F}_{2}, \mathrm{G}_{2}$, i.e. melt temperature $\left(170^{\circ} \mathrm{C}\right), \mathrm{EM}$ content $(0.5 \%)$, injection rate $(15 \mathrm{~mm} / \mathrm{s}), \mathrm{HGM}$ content $(6 \%)$, back pressure $(20$ bar $)$, mold temperature $\left(60^{\circ} \mathrm{C}\right)$ and screw rotation speed $(100 \mathrm{rpm})$.

Therefore, in relative terms it is possible to achieve an increase of the specific flexural modulus of around 26\%. (initial specific flexural modulus of $1425 \mathrm{Mpa}$ and optimized specific flexural modulus of $1796 \mathrm{Mpa})$.

\section{Declaration of conflicting interests}

The author(s) declared no potential conflicts of interest with respect to the research, authorship, and/or publication of this article. 


\section{Funding}

The author(s) disclosed receipt of the following financial support for the research, authorship, and/or publication of this article: The authors acknowledge the financial support from the "Ministerio de Economía y Competitividad" through the project MAT2017-85101-C2.

\section{ORCID iD}

José M Pastor (D) https://orcid.org/0000-0002-0197-3870

\section{References}

1. REGULATION (EC) $\mathrm{N}^{\circ} 443 / 2009$. Setting emission performance standards for new passenger cars as part of the Community's integrated approach to reduce $\mathrm{CO}_{2}$ emissions from light-duty vehicles. The European Parliament and The Council of the European Union. Brussels. 2009.

2. Decision $\mathrm{N}^{\circ} 1753 / 2000 /$ EC. A scheme to monitor the average specific emissions of $\mathrm{CO}_{2}$ from new passenger cars. Brussels: The European Parliament and The Council of the European Union, 2000.

3. Sadik T, Pillon C, Carrot C, Reglero-Ruiz JA, et al. Polypropylene structural foams: measurements of the core, skin, and overall mechanical properties with evaluation of predictive models. J Cell Plast 2017; 53: 25-44.

4. Demori R, Bischoff E, De Azevedo AP, et al. Morphological, thermo-mechanical, and thermal conductivity properties of halloysite nanotube-filled polypropylene nanocomposite foam. J Cell Plast 2018; 54: 217-233.

5. Dutta A, Sankarpandi S and Ghosh AK. Evaluation of polypropylene/clay nanocomposite foamability based on their morphological and rheological aspects. J Cell Plast 2018; 54: 829-850.

6. Okamoto K. Microcellular processing. Munich: Hanser Publishers, 2003, pp.1-13.

7. Michaeli W and Obeloer D. Foam injection moulding - specific adjustment of foam structure and mechanical properties. J Polym Eng 2011; 31: 353-359.

8. ABN Pipe Systems, S.L., ES Patent, 2364263 A1, 2011.

9. Heim H-P and Tromm M. Injection molded components with functionally graded foam structures - procedure and essential results. J Cell Plast 2016; 52: 299-319.

10. Bahreini E, Aghamiri SF, Wilhelm M, et al. Influence of molecular structure of polypropylene: linear and extensional rheological fingerprint. JCellPlast 2018; 54: 515-543.

11. Mörl M, Steinlein C, Kreger K, et al. Improved compression properties of polypropylene extrusion foams by supramolecular additives. JCellPlast 2018; 54: 483-498.

12. Murphy J. Additives for plastics handbook. 2nd ed. Oxford: Elsevier Science Ltd, 2001, pp.177-188.

13. Kawaguchi Y, Ito D, Kosaka Y, et al. Thermally expandable microcapsules for polymer foaming - relationship between expandability and viscoelasticity. Polym Eng Sci 2010; 50: 835-842.

14. Mae H, Omiya M and Kishimoto K. Effects of strain rate and density on tensile behavior of polypropylene syntactic foam with polymer microballoons. Mater Sci Eng A 2008; 477: 168-178.

15. Kawaguchi $Y$ and Oishi T. Synthesis and properties of thermoplastic expandable microspheres: the relation between crosslinking density and expandable property. $J$ Appl Polym Sci 2004; 93: 505-512. 
16. Kawaguchi Y, Itamura Y, Onimura K, et al. Effects of the chemical structure on the heat resistance of thermoplastic expandable microspheres. J Appl Polym Sci 2005; 96: $1306-1312$.

17. Jonsson $\mathrm{M}$, Nordin $\mathrm{O}$ and Malmström E. Increased onset temperature of expansion in thermally expandable microspheres through combination of crosslinking agents. $J$ Appl Polym Sci 2011; 121: 369-375.

18. Wouterson EM, Boey FYC, Hu X, et al. Specific properties and fracture toughness of syntactic foam: effect of foam microstructures. Compos Sci Technol 2005; 65: 1840-1850.

19. Fine T, Sautereau H and Sauvant-Moynot V. Innovative processing and mechanical properties of high temperature syntactic foams based on a thermoplastic/thermoset matrix. J Mater Sci 2003; 38: 2709-2716.

20. Patankar SN and Kranov YA. Hollow glass microsphere HDPE composites for low energy sustainability. Mater Sci Eng A 2010; 527: 1361-1366.

21. 3M Innovative Properties Company, U.S. Patent, 0116942 A1, 2007.

22. Taguchi G. Introduction to quality engineering. New York: McGraw-Hill, 1990.

23. Ross PJ. Taguchi techniques for quality engineering. 2nd ed. New York: Mc Graw-Hill, 1996.

24. John B and Reghunadhan CP. Update on syntactic foams. 1st ed. Shropshire: Smithers Rapra, 2010, pp.1-22.

25. Xanthos M. Glass and ceramic spheres. In: Xanthos M (ed.) Functional fillers for plastics. Weinheim: Wiley-VCH, 2005, pp.381-386.

26. Jonsson M, Nordin O, Malmström E, et al. Suspension polymerization of thermally expandable core/shell particles. Polymer 2006; 47: 3315-3324.

27. Roy RK. A primer on the Taguchi method. Michigan: Society of Manufacturing Engineers, 1990. 